\title{
Conclusive Growth of CdTe Nanorods by Solvothermal Decomposition Using Single Source Precursors
}

\author{
Arunendera Kumar Tiwari ${ }^{*}$, Vinay Kumar Verma ${ }^{2}$, Tripti A. Jain ${ }^{1}$, Parmendra Kumar Bajpai ${ }^{3}$ \\ ${ }^{1}$ Disha Institute of Management and Technology, Raipur, India; ${ }^{2}$ Department RTDC, Sharda University, Greater Noida, India; \\ ${ }^{3}$ Department of Pure and Applied Physics, Guru Ghasidas Vishwavidyalaya, Bilaspur, India. \\ Email: "bajpai.pk1@gmail.com
}

Received March $15^{\text {th }}, 2013$, revised April 20 ${ }^{\text {th }}, 2013$; accepted May $1^{\text {st }}, 2013$

Copyright (C) 2013 Arunendera Kumar Tiwari et al. This is an open access article distributed under the Creative Commons Attribution License, which permits unrestricted use, distribution, and reproduction in any medium, provided the original work is properly cited.

\begin{abstract}
CdTe nanorods are synthesized by solvothermal decomposition, using single source molecular precursors (SSMP) cadmium (II), complex of bis-(aminopropyl telluride) (SSMP-I) and cadmium (II) bis-(isopropyl telluro) propane (SSMP-II) and quinoline as solvent at relatively low temperature $\left(210^{\circ} \mathrm{C}\right)$. As synthesized nanomaterials are structurally characterized by XRD and SEM, SEM micrographs revealed formation of rod shapes structures whose dimensions change with the source precursor molecule. The average crystallite size estimated from XRD data is $29.78 \mathrm{~nm}$ and $28.94 \mathrm{~nm}$ respectively using Precursors I and II. The average size of nanorods is $1.237 \mu \mathrm{m}$ and $0.15 \mu \mathrm{m}$ respectively, estimated from SEM micrographs. These are much larger than the average crystallite size estimated from XRD data. This is attributed to the agglomeration of nanocrystallites as quinoline is not a good capping agent.
\end{abstract}

Keywords: Single Source Molecular Precursor; CdTe Nanorods; SEM; Solvothermal Synthesis

\section{Introduction}

There has been a tremendous interest in growth of metal chalcogenide nano-materials of varied shape (rods, wires, discs, etc.) over a last two decades with varied range of size and compositions [1]. One dimensional semiconductor nanocrystals having unique structural, optical and electrical properties have been considered as structural units for modern electronic devices, sensors, photonics materials, therefore, several synthetic routes have been employed for production nanorods and nanowires [2-9]. These include template directed method, vapor phase approach, vapor liquid solid growth, sol-gel technique, solvothermal synthesis, solution phase growth based on capping agents, sonochemical, radiolytic method among others reported. Each of these methods has its own merits and limitations [10]. Therefore, the need to develop different methodologies for synthesis of nanomaterials is inevitable in synthetic chemistry. Among the II-VI semiconducting nanomaterials, $\mathrm{CdS}$ and $\mathrm{CdSe}$ are widely synthesized, because of their high crystallites' size dependent features of photoluminescence and absorption [11] and great deal of work has been done to characterize

${ }^{*}$ Corresponding author.
$\mathrm{CdS}$ and CdSe nanocrystals. Reports on CdTe nanomaterials are very few. This is because tellurium anions susceptibility to aerial oxidation, and that it also requires higher temperature for the reduction of elemental tellurium during the synthesis organotelluride ligands $[12,13]$. Nanostructures such as nanorods and nanowires are reported to have better materials properties for solar cell applications in comparison to classical semiconductor, [14]; nanoparticles network charge can be transferred through the optimal arrangement of nanorods or nanowires without losses because of recombination at the nanoparticle boundaries in contrast to bulk semiconductor. Further, the energy band gaps of nanostructured materials are sensitive to their size of nanoparticles; hence, nanorods with varying diameter are more useful for solar cell application than nanoparticles and fix diameter nanorods [15]. CdTe nanorods are a better alternative for $\mathrm{CdS}$ because of smaller band gap $(\mathrm{Eg} \approx 1.45 \mathrm{eV})$ which it is easily adjusted to the solar spectrum [16].

In contrast to versatile method of synthesis of $\mathrm{CdTe}$ quantum dots [16-22], growth of one dimensional nanorods and nanowires is discussed rather limited in literature. Peng and Alivisatos [8] have reported the synthesis of CdSe nanorods, CdTe [23] nanorods and branched 
nanorods $[7,16]$ using binary mixture of the surfactant hexylphosphonic acid and trioctylphosphonic oxide. They have achieved impressive results by controlling the length of CdSe nanorods [16,24-27]. Guo, et al. [28] prepared array of CdTe nanowires by dc electrochemical deposition using porous aluminum oxide as a template. Growth of CdTe nanorods has also been demonstrated using catalytic driven pulsed laser deposition (PLD) technique, in which selective area epitaxy on sapphire substrate and a catalytically driven vapor liquid solid growth have been found critical for the growth of 1D nanomaterials [29]. Li, et al. [30] reported water soluble CdTe nanorods prepared with the assistance of mixed ligand system of cysteine and thioglycolic acid; the aspect ratio and photoluminescence controlled by the refluxing time. Multi armed CdTe nanorods were prepared by Nie, et al. [31] using myristic acid as complexing agent. Wang, et al. [32] prepared CdTe nanorods with diameter of $150 \mathrm{~nm}$ and $1 \mu \mathrm{m}$ length using thermal chemistry method. An attractive route for the preparation of nanostructures has been the decomposition of single source of molecular precursor, using non-aqueous high boiling co-coordinating solvent such as trioctylphosphine and its oxides $[33,34]$. The use of single source molecular precursor (SSMP) having metal chalcogen bond is very efficient route for generation of metal chalcogenide nanomaterials.

In this paper, we report the synthesis of CdTe nanorods using solvothermal route from two different single source molecular precursors and their subsequent characterization by XRD and SEM.

\section{Experimental}

All chemicals used were of analytical grade and were of highest purity, Tellurium powder (99.99\% 200 mesh), $\mathrm{NaBH}_{4}$ (AR), Tetrahydrofuran (THF), 1, 3 dibromopropane, isopropyl bromide were purchased from Merck brand, 3-Chloroethylamine hydrochloride (sigma Aldrich) Methanol purchased from Fischer scientific.

\subsection{Synthesis Cadmium Telluride Nanomaterial}

Single source precursor Cadmium complex of bis-(aminopropyl telluride) were reported earlier [35]. The CdTe nanomaterial using SSMP-I is synthesized as shown in Scheme 1. Briefly by reduction of elemental tellurium with $\mathrm{NaBH}_{4}$, disodium telluride 1) is formed in which 3-Chloroethyl amine hydrochloride is added and stirred for 6 hours, bis-(isopropyl) telluride; 2) is formed. The precursor then extracted by dichloromethane, washed with distilled water, dried over $\mathrm{Na}_{2} \mathrm{SO}_{4}$ and filtered off. The material was dried in vacuum in a desiccator. Calculated amount of ligand is reacted with anhydrous cadmium chloride in 1:1 in methanolic solution, pale yellow colored Cd (II) complex of bis-(aminopropyl) telluride; 3) is obtained. Thermolysis of this complex is carried out at $200^{\circ} \mathrm{C}$; quinoline is used as a capping agent. Blackish powder of CdTe; 4) nanomaterials is obtained.

Single source molecular precursor Cd (II) complex of bis-(isopropyl telluro) propane [36] were also known. In the present work, this precursor is prepared by some modification as shown in Scheme 2. First, elemental tellurium is reduced by NaBH4 in alkaline THF under argon gas atmosphere, di-sodium telluride. i), This is formed, which is converted into disodium di-telluride. This is reacted with isopropyl bromide to form bis-(isopropyl) ditelluride; ii), separated, and reduced by $\mathrm{NaBH}_{4}$ under argon gas atmosphere, 1, 3-dibromopropane is added to it. Pale yellow viscous product of bis-(isopropyl telluro) propane; iii), is formed. The product is reacted to $\mathrm{Cd}$ (II) chloride in dry acetonitrile at 1:1, pale yellow $\mathrm{Cd}$ (II) complex of bis-(isopropyltelluro propane) (iv) is obtained. It is pyrolysed at $205^{\circ} \mathrm{C}$; grey colored CdTe (v) nanomaterials were generated.

$$
\begin{aligned}
& \mathrm{Te}^{0}+2 \mathrm{NaBH}_{4} \frac{\mathrm{Ar} \text { gas, } 60^{\circ} \mathrm{C}-70^{\circ} \mathrm{C}}{\mathrm{THF}, \mathrm{H}_{2} \mathrm{O}} \mathrm{Na}_{2} \mathrm{Te} \stackrel{\mathrm{Cl}\left(\mathrm{CH}_{2}\right)_{3} \mathrm{NH}_{2} \mathrm{HCl}}{\longrightarrow} \\
& \text { (1) Disodium telluride } \\
& \text { (2) [bis(aminopropyl)telluride] } \\
& + \\
& \text { Methanol }
\end{aligned}
$$

(4) $[\mathrm{Cd}(\mathrm{II})$ complex of bis(aminopropyl)telluride]

Scheme 1. Synthesis of CdTe nanomaterial from SSMP-I. 


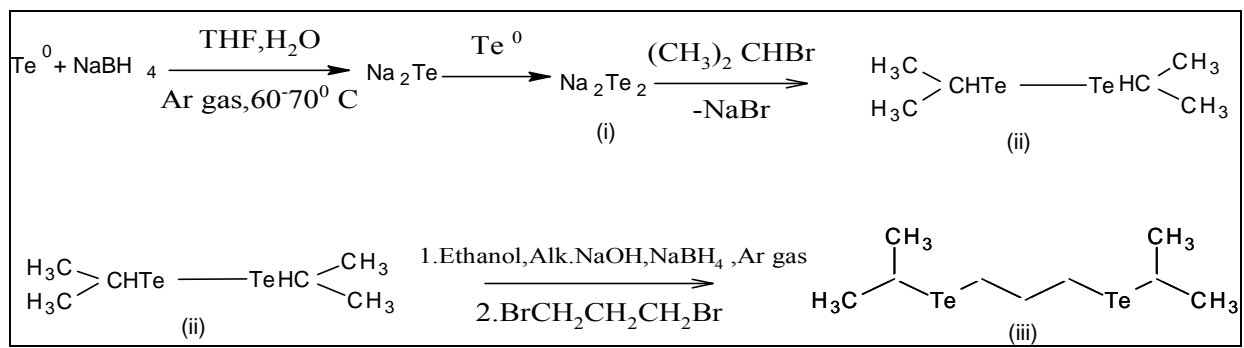

(a)

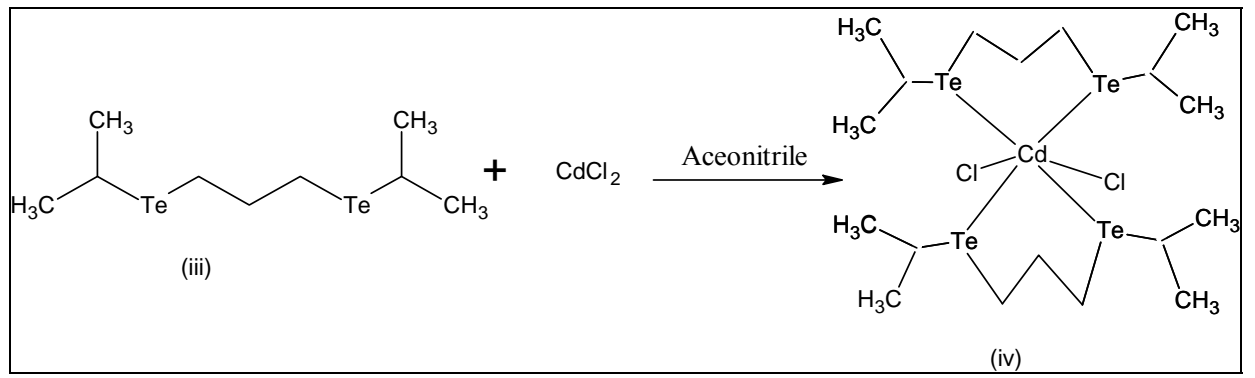

(b)

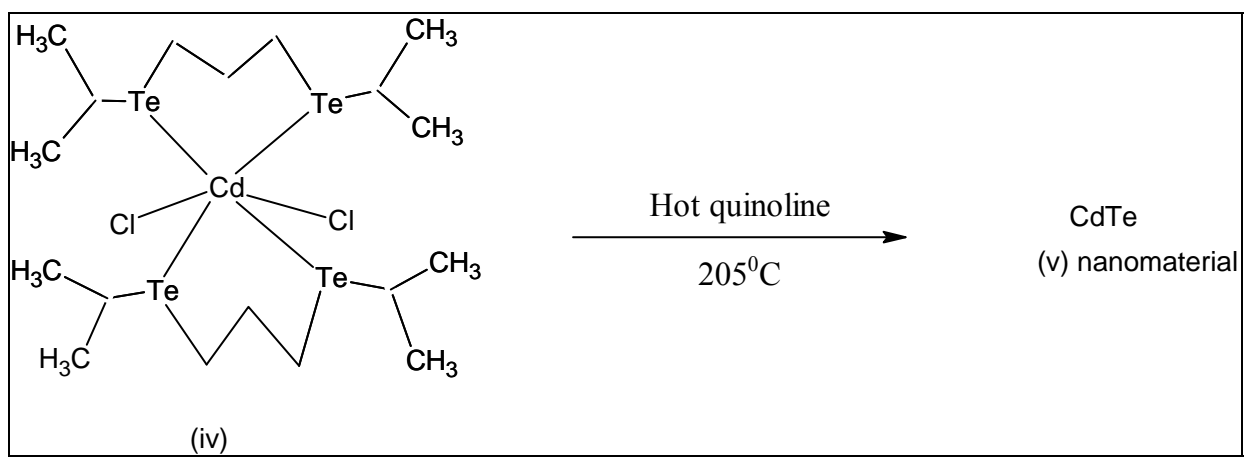

(c)

Scheme 2. Synthesis of CdTe nanomaterial from SSMP-II.

\section{Results and Discussion}

X-ray diffraction pattern of blackish powder of CdTe nanoparticles, obtained by thermolysis of single source molecular precursor Cadmium (II) complex of bis-(aminopropyl) telluride (SSMP-I), is shown in Figure 1, whereas XRD pattern of grey powder CdTe obtained by thermolysis of single source precursor Cadmium (II), complex of bis-(isopropyltelluro) propane (SSMP-II), is shown in Figure 2. The observed XRD pattern matches closely with JCPDS file No. 75 - 2083 confirming face centered cubic structure of crystallites with lattice parameter $\left(\mathrm{a}=6.410 \mathrm{~A}^{0}\right)$ for CdTe nanoparticles preparedfrom SSMP-I. The XRD pattern of nanoparticles obtained from SSMP-II matches with JCPDS file No. 75 2083, which again have face centered cubic structure of crystallites with same lattice parameter as estimated for nanoparticles obtained from single source molecular precursor-I.

Average particle size of crystallites is calculated by Debye Scherer equation.

$$
\tau=\frac{k \lambda}{\beta \cos \theta}
$$

where $k$ is the shape factor, the dimensionless shape factor has typical value $0.9, \lambda$ is the $\mathrm{X}$-ray wavelength 0.154 $\mathrm{nm}$., $\beta$ is the line broadening at half the maximum intensity (FWHM) in radians, and $\theta$ is the Bragg angle; $\tau$ is the mean size of the ordered (crystalline) domains, which may be smaller or equal to the grain size. Average sizes of crystallite calculated from Debye Scherer equation, are $29.78 \mathrm{~nm}$ and $28.94 \mathrm{~nm}$, respectively for CdTe nanoparticles obtained from SSMP-I and II.

Micro structural Characterization is made by Scanning electron microscope (SEM). SEM micrographs of the prepared nanomaterials from SSMP-I is shown in Figure 3. SEM micrograph of CdTe powder showed formation of some micro size rods along with agglomerated particles; diameter of rods being $1.125-1.35 \mu \mathrm{m}$ and average length more than $5 \mu \mathrm{m}$. Thus, SSMP-I does not lead to nanostructure formation. 


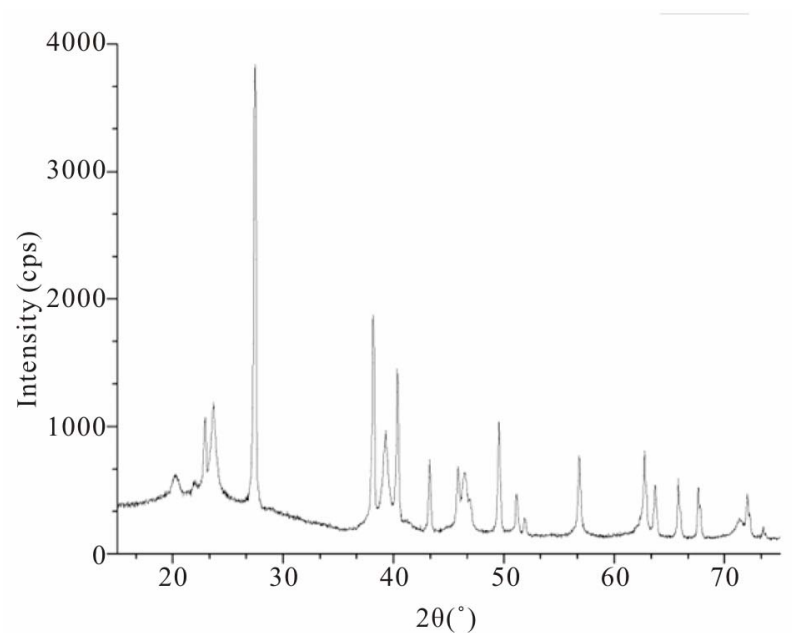

Figure 1. Powder X-ray diffraction pattern of CdTe (d) nanoparticles obtained by thermolysis of single source molecular precursor Cadmium (II) complex of bis-(aminopropyl) telluride.

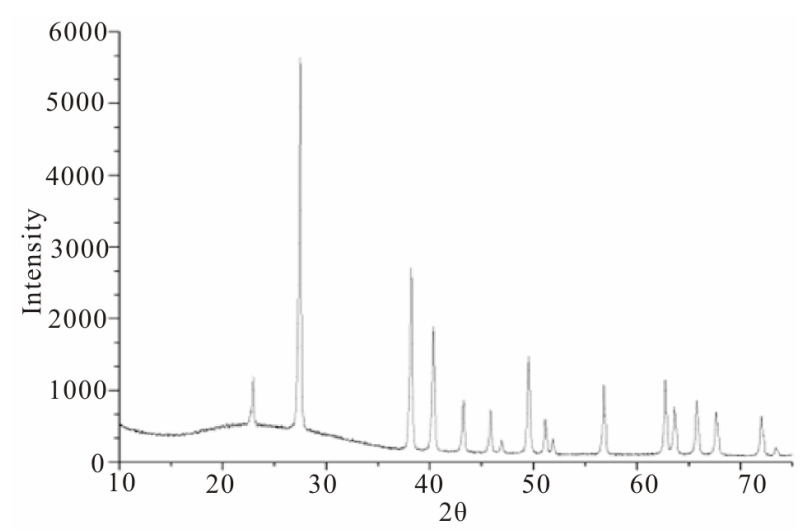

Figure 2. Powder X-ray diffraction pattern of CdTe nanoparticles obtained by thermolysis of single source precursor Cadmium (II) complex of bis-(isopropyltelluro) propane.

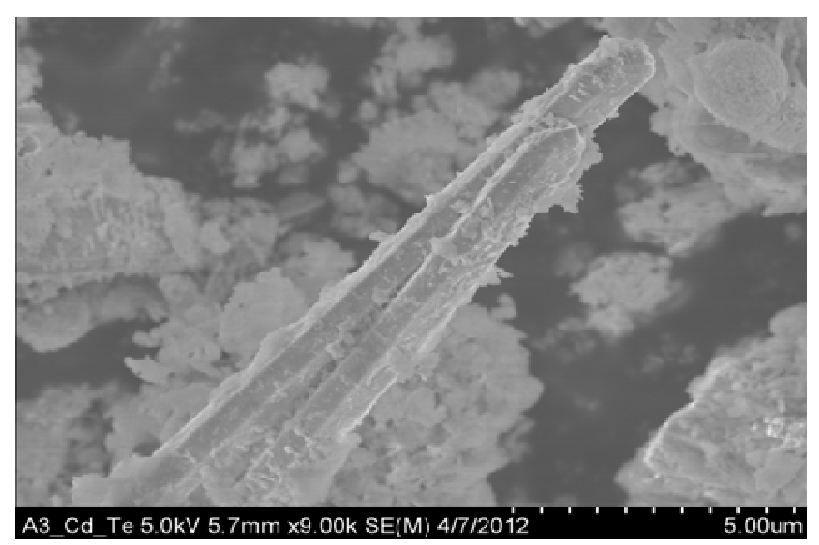

Figure 3. SEM micrograph of CdTe powder prepared from single source molecular precursor Cadmium (II) complex of bis-(aminopropyl) telluride.

On the other hand, SEM micrograph of CdTe powder

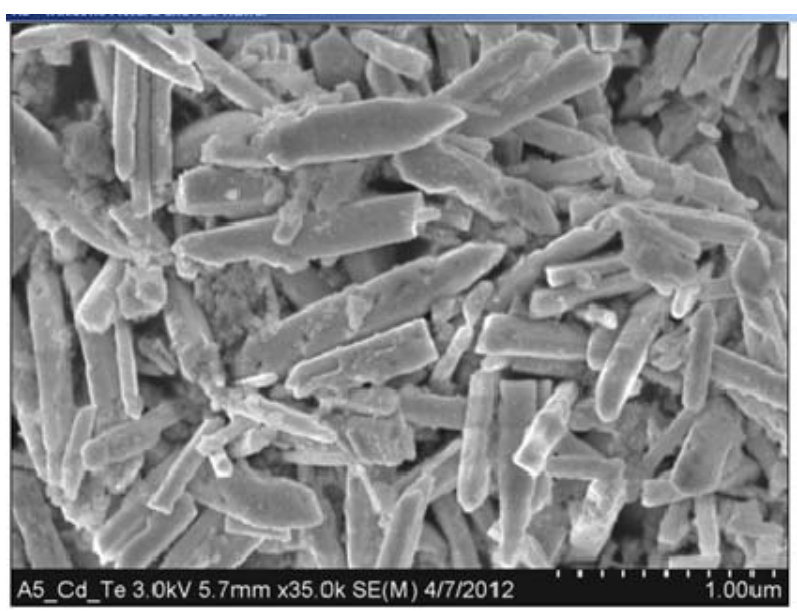

Figure 4. SEM images of CdTe nanorods obtained from Cadmium (II) complex of bis-(isopropyltelluro) propane.

obtained from SSMP-II in Figure 4, exhibits surface morphology with homogeneously distributed nanorods, diameter of rods are $100-200 \mathrm{~nm}$ and average length in submicron range.

\section{Conclusion}

Single source molecular precursor Cd (II) complexes of bis-(aminopropyl) telluride and bis-(isopropyltelluro) propane were prepared, and their subsequent decomposition in CdTe nanomaterials. Both SSMP yielded CdTe rods with varying diameters. Later gave uniform nanorods with smaller diameter in nano dimensions. XRD characterization of both nanomaterials matches with JCPDs file, and the nanorods are oriented randomly with an average diameter of $1.237 \mu \mathrm{m}$ and $0.15 \mu \mathrm{m}$. In addition, each nanorod seems to become posed of a number of nano crystals stacking along the rod growth direction.

\section{Acknowledgement}

Thanks to DRDO New Delhi, providing financial support and award of fellowship to AKT and also thankful to Prof. S. K. Mukherjee (Director, renewable energy technology, Egan research center, Boston USA) providing useful facilities for characterization of nanomaterials.

\section{REFERENCES}

[1] W. Wang, C. Chen, K.-H. Lin, Y. Fang and C. M. Lieber, Nanosensors. US 2007/0264623 A1, 2007.

[2] H. Dai, E. W. Wong, Y. Z. Lu, S. Fan and C. M. Lieber, "Synthesis and Characterization of Carbide Nanorods," Nature, Vol. 375, No. 6534, 1995, pp. 769-772. doi: $10.1038 / 375769 \mathrm{a} 0$

[3] X. F. Duan, Y. Huang, Y. Cui, J. F. Wang and C. M. Lieber, "Indium Phosphide Nanowires as Building Blocks for Nanoscale Electronic and Optoelectronic Devices," 
Nature, Vol. 409, No. 6816, 2001, pp. 66-69.

[4] J. D. Holmes, K. P. Johnston, R. C. Doty and B. A. Korgel, "Control of Thickness and Orientation of SolutionGrown Silicon Nanowires," Science, Vol. 287, No. 5457, 2000, pp. 1471-1473.

[5] B. Gates, Y. Wu, Y. Yin, P. Yang and Y. Xia, "Single-Crystalline Nanowires of $\mathrm{Ag}_{2} \mathrm{Se}$ Can Be Synthesized by Templating against Nanowires of Trigonal Se," Journal of the American Chemical Society, Vol. 123, No. 46, 2001, pp. 11500-11501. doi:10.1021/ja0166895

[6] C. R. Martin, "Nanomaterials: A Membrane-Based Synthetic Approach," Science, Vol. 266, No. 5193, 1994, pp. 1961-1966. doi:10.1126/science.266.5193.1961

[7] X. G. Peng, L. Manna, W. D. Yang, J. Wickham, E. Scher, A. Kadavanich and A. P. Alivisatos, "Shape Control of CdSe Nanocrystal," Nature, Vol. 404, No. 6773, 2000, pp.59-61.

[8] S. R. Nicewarner-Pena, et al., "Submicrometer Metallic Barcodes," Science, Vol. 294, No. 5540, 2001, pp. 137141. doi:10.1126/science.294.5540.137

[9] J. S. Yu, et al., "Template Synthesis of Polymer-Insulated Colloidal Gold Nanowires with Reactive Ends," Chemical Communications, No. 24, 2000, pp. 2445-2446. doi:10.1039/b007999p

[10] X. Wang and Y. D. Li, "Selected-Control Hydrothermal Synthesis of $\alpha$ - and $\beta-\mathrm{MnO}_{2}$ Single Crystal Nanowires," Journal of The American Chemical Society, Vol. 124, No. 12, 2002, pp. 2880-2881. doi:10.1021/ja0177105

[11] A. P. Alivisatos, "Semiconductor Clusters, Nanocrystals, and Quantum Dots," Science, Vol. 271, No. 5251, 1996, pp. 933-937.

[12] M. L. Striegerwald and L. E. Brus, "Synthesis, Stabilization, and Electronic Structure of Quantum Semiconductor Nanoclusters," Annual Review of Materials Science, Vol. 19,1989, pp. 471-495.

doi:10.1146/annurev.ms.19.080189.002351

[13] M. D. Milton, S. Khan, J. D. Singh, V. Mishra and B. L. Khandelwal, "A Facile Access to Chalcogen and Dichalcogen Bearing Dialkylamines and Diols," Tetrahedron Letters, Vol. 46, No. 5, 2005, pp. 755-758. doi:10.1016/j.tetlet.2004.12.035

[14] Y. J. Wu, H. Q. Yan and P. D. Yang, "Semiconductor Nanowire Array: Potential Substrates for Photocatalysis and Photovoltaics," Topics in Catalysis, Vol. 19, No. 2, 2002, pp. 197-202. doi:10.1023/A:1015260008046

[15] B. R. Mehta andF. E. Kruis, "A Graded Diameter and Oriented Nanorod-Thin Film Structure for Solar Cell Application: A Device Proposal," Solar Energy Material and Solar Cells, Vol. 85, No. 1, 2005, pp. 107-113.

[16] L. Manna, D. J. Milliron, A. Meisel, E. C. Scher and A. P. Alivisatos, "Controlled growth of Tetrapod-Branchedinorganic Nanocrystals," Nature Materials, Vol. 2, 2003, pp. 382-385.

[17] Y. Terai, S. Kuroda, K. Takita, T. Okuno and Y. Masumoto, "Zero-Dimensional Excitonic Properties of SelfOrganized Quantum Dots of CdTe Grown by Molecular Beam Epitaxy," Applied Physics Letters, Vol. 73, No. 25, 1998, Article ID. 3757. doi:10.1063/1.122885
[18] H. Zhang, L. P. Wang, H. M. Xiong, L. H. Hu, B. Yang and W. Li, "Hydrothermal Synthesis for High-Quality CdTe Nanocrystals," Advanced Materials, Vol. 15, No. 20, 2003, pp. 1712-1715. doi:10.1002/adma.200305653

[19] S. F. Wuister, I. Swart, F. Van Driel, S. G. Hickey and C. D. Donega, "Highly Luminescent Water-Soluble CdTe Quantum Dots," Nano Letters, Vol. 3, No. 4, 2003, pp. 503-507. doi:10.1021/n1034054t

[20] Y. Bae, N. Myung and A. J. Bard, "Electrochemistry and Electrogenerated Chemiluminescence of CdTe Nanoparticles," Nano Letters, Vol. 4, No. 6, 2004, pp. 1153-1161. doi:10.1021/n1049516x

[21] X. G. Peng, L. Manna, W. D. Yang, J. Wickham, E. Scher, A. Kadavanich and A. P. Alivisatos, "Shape Control of CdSe Nanocrystals," Nature, Vol. 404, No. 6773, 2000, pp. 59-61.

[22] P. D. Cozzoli, T. Pellegrino and L. Manna, "Synthesis Properties and Perspectives of Hybrid Nanocrystalstructures," Chemical Society Reviews, 2006, Vol. 35, 2006, pp. 1195-1208.

[23] Y. Kang, N.-G. Park and D. Kim, "Hybrid Solar Cells with Vertically Aligned CdTe Nanorods and a Conjugated Polymer," Applied Physics Letters, Vol. 86, No. 11, 2005, pp. 113101-113103.

[24] L. Manna, E. C. Scher and A. P. Alivisatos, "Synthesis of Soluble and Processable Rod-, Arrow-, Teardrop-, and Tetrapod-Shaped CdSe Nanocrystals," Journal of American Chemical Society, Vol. 122, No. 51, 2000, pp. 1270012706. doi: $10.1021 / \mathrm{ja} 003055+$

[25] D. J. Milleron, I. Gur and A. P. Alivisatos, "Hybrid Organic-Nanocrystal Solar Cells," MRS Bulletin, Vol. 30, No. 1, 2005, pp. 41-44. doi:10.1557/mrs2005.8

[26] S. Neretina, R. A. Hughes, G. A. Devenyi, N. V. Sochinskii, J. S. Preston and P. Mascher, "The Role of Substrate Surface Alteration in the Fabrication of Vertically Aligned CdTe Nanowires," Nanotechnology, Vol. 19, No. 18, 2008, Article ID. 185601. doi:10.1088/0957-4484/19/18/185601

[27] N. C. Greenham, X. Peng and A. P. Alivisatos, "Charge Separation and Transport in Conjugated-Polymer/Semiconductor-Nanocrystal Composites Studied by Photoluminescence Quenching and Photoconductivity," Physical Review B, Vol. 54, 1996, pp. 17628-17637. doi:10.1103/PhysRevB.54.17628

[28] D. S. Xu, D. P. Chen, Y. J. Xu, X. S. Shi, G. L. Guo, L. L. Gui and Y. Q. Tang, "Preparation of II-VI Group Semiconductor Nanowire Arrays by dc Electrochemical Deposition in Porous Aluminum Oxide Templates," Pure and Applied Chemistry, Vol. 72, No. 1-2, 2000, pp. 127-135. doi:10.1351/pac200072010127

[29] S. Neretina, R. A. Hughes, J. F. Britten, N. V. Sochinskii, J. S. Preston and P. Mascher, "Vertically Aligned Wurtzite CdTe Nanowires Derived from a Catalytically Driven Growth Mode," Nanotechnology, Vol. 18, No. 27, 2007, Article ID. 275301. doi:10.1088/0957-4484/18/27/275301

[30] J. Li, X. Hong, D. Li, K. Zhao, L. Wang, H. Z. Wang, Z. L. Du, J. H. Li, Y. B. Bai and T. J. Li, "Mixed Ligand System of Cysteine and Thioglycolic Acid Assisting in 
the Synthesis of Highly Luminescent Water-Soluble CdTe Nanorods," Chemical Communications, 2004, pp. 1740-1741.

[31] W. Nie, J. B. He, N. N. Zhao and X. L. Ji, "A Controllable Synthesis of Multi-Armed CdTe Nanorods," Nanotechnology, Vol. 17, No. 4, 2006, Article ID. 1146. doi:10.1088/0957-4484/17/4/050

[32] X. N. Wang, J. Wang, M. J. Zhou, H. Wang, X. D. Xio and Q. Li, "CdTe Nanorods Formation via Nanoparticle self-Assembly by Thermal Chemistry Method," Journal of Crystal Growth, Vol. 5, No. 16-17, 2010, pp. 32102314.

[33] T. Trindade and P. O'Brien, “A Single Source Approach to the Synthesis of CdSe Nanocrystallites," Advanced Materials, Vol. 8, No. 2, 1996, pp. 161-163.
[34] M. D. Milton, S. Khan, J. D. Singh, V. Mishra and B. L. Khandelwal, "A Facile Access to Chalcogen and Dichalcogen Bearing Dialkylamines and Diols," Tetrahedron Letters, Vol. 46, No. 5, 2005, pp. 755-758.

[35] M. D. Milton, J. Singh, J. D. Singh, B. L. Khandelwal and R. J. Butcher, "Design, Synthesis and Structural Aspects of $\mathrm{NH} 2(\mathrm{CH} 2) \mathrm{nE}(\mathrm{CH} 2) \mathrm{nNH} 2(\mathrm{n}=2$ or $3 ; \mathrm{E}=\mathrm{Se}$ or $\mathrm{Te})$ $\mathrm{N} 2 \mathrm{Se}$ or N2Te Donors and its Complexes with Group 12 Metals," Phosphorus, Sulfur, and Silicon and the Related Elements, Vol. 172, No. 1, 2001, pp. 239-246.

[36] D. Selvakumar, R. Singh, M. Nasim, G. N. Mathur, "Synthesis of Bis(alkyltelluro) Methanes and Their Complexation with Cadmium(II)," Phosphorus, Sulfur, and Silicon and the Related Elements, Vol. 172, No. 247, 2001, pp. 501-513. 